\title{
MULHERES NO MUNDO MUÇULMANO E 0 ATIVISMO PARA OS DIREITOS HUMANOS
}

\author{
WOMEN IN THE MUSLIM WORLD \\ AND HUMAN RIGHTS ACTIVISM
}

\author{
Evelyn Faria da Silva Luz ${ }^{1}$
}

\begin{abstract}
RESUMO: Os Direitos Humanos surgiram com caráter universal e generalista. Dessa forma, seus preceitos deveriam ser úteis para todos e todas. Todavia, no primeiro momento em que foi pensado - a partir de um ponto de vista masculinista - não foram incluídos direitos e demandas específicas das mulheres. Esse contexto foi mudado a partir do processo de especificação do sujeito de direito, que resultou em documentos voltados exclusivamente para elas, a partir do ativismo, incluía-se os Direitos Humanos das mulheres no cenário internacional. No entanto, o referencial criado foi criticado por feministas de fora do norte global por representar demasiadamente uma ótica branca e ocidental. Este artigo traz o caso específico das muçulmanas, apresentando como o ativismo delas se dá no sentido de trazer o instrumental de Direitos Humanos para sua realidade. Para tanto, nesse trabalho, abordam-se os desafios em geral enfrentados por esse grupo de mulheres e como estas agem. Destaca-se a importância dessas novas vozes, tanto no cenário internacional quanto no processo de internalização no âmbito local, para a maior eficácia e legitimidade dos Direitos Humanos.
\end{abstract}

Palavras-chave: Direitos Humanos; Mulheres; Muçulmanas; Ativismo
ABSTRACT: Human rights emerged with a universal and generalist character, their precepts should be useful for everyone. However, in this first moment, which was mainly thought -from a masculine perspective- specific rights and demands of women were not included. This context was changed from the process of specifying the subject of law, which resulted in documents focused exclusively on women, from activism, women included their human rights the international agenda. However, the framework created has been criticized by feminists from outside the global north, they point out how it may represent a white and western point of view. This article presents the specific case of Muslim women, discussing how their activism aims to bring the instrumentality of Human Rights to their reality. Therefore, this paper addresses the general challenges faced by this group of women and how they act upon it. We highlight the importance of these new voices, both in the international scenario and in the process of internalization at the local level, for the greater effectiveness and legitimacy of Human Rights.

Keywords: Human Rights; Women; Muslims; Activism.

\section{Introdução}

Os Direitos Humanos se tornaram tema caro na academia bem como no cenário internacional principalmente a partir da Segunda Guerra Mundial. Sendo assim, desde então, muito é tratado sobre o assunto seja no âmbito de organismos internacionais, refletindo-se em convenções, seja no meio acadêmico, com uma variedade de obras.

\footnotetext{
${ }^{1}$ Evelyn Faria da Silva Luz é graduada em relações internacionais pela Universidade Federal de Roraima (UFRR), trabalha com a causa do fluxo de venezuelanas para o Brasil e o recorte de gênero no refúgio e migrações. Link para currículo lattes: http://lattes.cnpq.br/1452383531677559. E-mail para contato: evelynluz11@gmail.com. ORCID ID: https://orcid.org/0000-0002-0810-5849
} 
Ressalta-se que a construção histórica do referencial instrumental e teórico de Direitos Humanos se deu com forte caráter de proteção geral e universalista. Este preocupava-se demasiadamente em endereçar seus preceitos a toda e qualquer pessoa e com a igualdade formal de todos perante a lei. Esquecia-se, assim, que o processo de violação dos Direitos Humanos alcança de maneira diferenciada certos grupos sociais, como as mulheres.

Essa generalidade recebeu críticas, destacando-se aqui as das feministas. Nesse sentido, a partir do ativismo que chegou até fóruns internacionais, e no contexto do alargamento do sujeito de direito, vitórias foram conquistadas por grupos de mulheres, repercutindo no âmbito das Nações Unidas e em novos documentos como a Convenção sobre a Eliminação de Todas as Formas de Discriminação Contra as Mulheres (CEDAW).

Entretanto, percebeu-se que os Direitos Humanos das mulheres ainda tinham uma perspectiva majoritariamente ocidental, apresentada como paradigmática. Havia-se generalizado a categoria mulher e suas questões, tal fato fez com que o referencial de Direitos Humanos não fosse significativo para várias delas. Nesse sentido, o processo de especificação acabou se mostrando insuficiente, pois questões e demandas de certos grupos de mulheres haviam sido esquecidos.

Com bases nesses aspectos, ao analisar o exemplo muçulmano, esse trabalho questiona se o referencial de Direitos Humanos existente é eficaz para os diferentes grupos de mulheres ao redor do mundo. A discussão pauta-se na ausência de uma diversidade de vozes femininas no cenário internacional, no qual esses direitos são pensados e questões discutidas, problematizando se eles não estão demasiadamente em uma perspectiva dos países desenvolvidos.

Existe uma variedade de conjunturas na região estudada, percebe-se que, cada vez mais, diferentes iniciativas locais que reivindicam direitos e liberdade estão desafiando o mito da passividade das mulheres muçulmanas. Nesse sentido, no presente artigo busca-se fazer uma análise geral das realidades das muçulmanas, os desafios encontrados e como elas os enfrentam, e de que forma fatores como o gênero moderam a interação delas com o Estado, a religião e a demanda por Direitos Humanos.

Não se pretende aqui, generalizar o que é ser mulher muçulmana, suas lutas e facetas. Reconhecendo a diversidade inerente ao grupo de estudo, objetiva-se aqui apresentar um panorama de como essas mulheres vêm garantido, de diversas formas, o cumprimento de seus Direitos Humanos e quebrando estereótipos. Desse modo, existe uma variedade de experiências e pontos de vista a partir de suas diferenças, e essas múltiplas perspectivas demandam ser compreendidas para que o referencial existente de Direitos Humanos faça sentido para todas.

Ou seja, entendendo que a universalidade e eficácia dos Direitos Humanos requerem um processo de desenvolvimento de mecanismos para implementações e reforços destes, procura-se entender de que maneira as mulheres muçulmanas, em suas variadas realidades, realizam isso. Pretende-se, assim, compreender como essas novas perspectivas, lutas e 
demandas são essenciais para agregar os Direitos Humanos à sua legitimidade e efetividade nos contextos locais.

\section{Mulheres No Mundo Muçulmano}

Mulheres em sociedades islâmicas, de maneira variada, continuam enfrentando limitações à sua participação na vida política, econômica e social, acesso à oportunidades de emprego e à educação formal, discriminação e outras lacunas significativas na equidade de gênero (YUSUF SIDANI. p.502. 2005). Os problemas nessas nações chegam até mesmo à negação dos direitos, restrições de fala, movimento e liberdade (AZIZAH AL-HIBRI. p. 57. 1998).

Esse contexto e a consolidação de regimes baseados no fundamentalismo islâmico abriram o debate sobre a posição das mulheres nessas sociedades. No cenário internacional, países muçulmanos passaram a ser vistos como inimigos dos Direitos Humanos (MÁRIO LOSANO p.405. 2007). Deve-se ressaltar que não é possível pensar que algumas sociedades consentem e apliquem todo o rol dos Direitos Humanos perfeitamente enquanto outras não apoiem nenhum, o tema é foco de tensão por todo o mundo (AN-NA'IM, 1995 apud MÁRCIA BARATTO. p. 56. 2009).

Nesse sentido, deve-se evitar generalizações, haja vista que o Islamismo é composto por várias vertentes e correntes e mesmo dentro de um único Estado pode haver uma pluralidade de visões. Logo, é necessário se informar sobre a realidade sociopolítica e não aplicar esquemas gerais predeterminados que por vezes são comprometidos por preconceitos etnocêntricos e políticos (MÁRIO LOSANO. p.400. 2007).

Entretanto, percebe-se que a islamização das relações de gênero, em geral, pode aprofundar a opressiva estrutura patriarcal (SHAHZARD MOJAB. p.130. 2001). Várias barreiras restringem as liberdades das mulheres em diversos âmbitos e em vários países, nos quais a discriminação geralmente ocorre em um ambiente de violência e subordinação socialmente toleradas (PNUD, 2016). Símbolos como a identidade islâmica com seu modo obrigatório de se vestir, sua moral e ordem, das quais a mulher é a guardiã, representam desafios a elas e à garantia de seus direitos (MAHAMOOD MONSHIPOURI. p.188. 2004).

Mesmo que haja tratados internacionais para garantir a igualdade de direitos, se estes dependerem exclusivamente da implementação governamental são menos prováveis de serem efetivos na prática (NATALIE KAUFMAN; STEFANIE LINDQUIST. p. 105. 1995). Nem sempre é possível contar com a iniciativa dos Estados, cujas reformas e ações promovidas muitas vezes são motivadas por interesses, que, em sociedades patriarcais, geralmente são obstáculos aos direitos das mulheres (MONSHIPOURI. p.188. 2004).

Mesmo que alguns desses Estados tenham o reconhecimento constitucional da igualdade, a maioria dos países árabes não têm leis que proíbam diretamente a discriminação de gênero (PNUD,2016) e nem têm um histórico de respeito aos Direitos Humanos das 
mulheres. Ademais, Estados com ideias afins sobre o tema como Irã e Arábia Saudita procuraram fomentar a ideia de que o Islamismo é uma religião que rejeita os valores do sistema de Direitos Humanos da ONU (ANN MAYER. p.68. 2007).

Nesse contexto, eles patrocinaram iniciativas como a Declaração do Cairo sobre Direitos Humanos no Islã de 1990, apresentada pela Organização da Conferência Islâmica como uma versão do que se diz ser Direitos Humanos islâmicos. Além de afirmar que todos os direitos estavam submetidos à lei islâmica, o documento não continha nenhum ponto garantindo igualdade para as mulheres. Iniciativas como essa, além de tentar restringir o direito internacional dos Direitos Humanos, diluem ou até mesmo eliminam liberdades civis e políticas e, ao fazer isso, fortalecem regimes autocráticos e hierarquias tradicionais (ANN MAYER. p.74. 2007; p.106. 1995).

Mahmood Monshipouri (2004), acrescenta que além de política, perpetuada pelo Estado, a fonte de controle patriarcal também é jurídica. A realidade cultural dos muçulmanos é pautada em sistemas legais que desempenham um papel importante como uma ferramenta organizacional básica, e a ligação da religião com a lei e os costumes têm profundas repercussões para as mulheres, afetando-as negativa e desproporcionalmente (FARIDA SHAHEED. p.997. 1994).

Pode-se afirmar que, em geral, o islamismo produz impactos em variados aspectos da vida de seus seguidores, não se restringindo ao âmbito do culto religioso e de ditames morais, mas também incluindo orientações, direitos e deveres que se propõem a reger a relação entre as pessoas (MUTADÃ MUTAHHARI. p.109. 1998). “ O Islã é também uma ordem social que tem uma influência onipresente em seus seguidores" (SIDANI, 2005 p. 499, tradução nossa).

Nesse sentido, a ciência jurídica está também vinculada à teologia, já o direito muçulmano mostra-se como um sistema filosófico desenvolvido a partir de princípios fundamentais ligados ao texto sagrado, o Alcorão. 0 conjunto de normas baseadas no livro sagrado recebe o nome de sharia, que significa o caminho a seguir. Nele estão inseridas regras de direito privado, penais, processuais, mas também teológicas, religiosas, morais e rituais (MÁRIO LOSANO.p. 423. 2007).

Um exemplo é o direito ligado ao âmbito da família, este ao se dirigir a ela estabelece normas, que regulamentam o casamento, divórcio, herança. (MÁRIO LOSANO. P.436. 2007). Assim, leis que regem questões pessoais e familiares são reguladas quase universalmente pela jurisprudência muçulmana e justificadas por referência a injunções islâmicas (FARIDA SHAHEED. p.997 1994).

Outrossim, a regulamentação de assuntos familiares e pessoais geralmente opera em oposição às mulheres. A família, em geral, tem um forte significado em grande parte do mundo muçulmano, entendendo-se esta vinculada à própria representação identitária (FARIDA SHAHEED. p.998. 1994). Movimentos conservadores usam essa simbologia para tentar reforçar o papel da mulher exclusivamente relacionado ao âmbito maternal e ao núcleo familiar (MOGHADAM, 2003 apud MAHAMOOD MONSHIPOURI. p.205. 2004). 
Assim, direitos particulares, como o à liberdade de religião ou à proteção da família, podem de fato serem usados como ferramenta para opressão das mulheres, que são vistas em termos de tutela e autoridade masculinas (HILARY CHARLESWORTH, 1994 p.55; PNUD, 2016). Desse modo, dependendo do país e do contexto, elas precisam pedir permissão ao pai, ou à outra figura masculina, para viajar, casar, procurar emprego e outros (MOGHADAM, 2003 apud MONSHIPOURI. p.205 2004), tudo isso, às vezes, previsto por lei.

Ademais, normas sociais e econômicas que colocam os homens como chefes de família e mulheres como cuidadoras não são os únicos problemas. A questão da herança é outro exemplo, as mulheres recebem uma cota inferior aos herdeiros homens. A maioridade delas é entendida no sentido biológico, coincidindo com a puberdade, por isso, no direito em questão elas se tornam puníveis antes dos homens (MÁRIO LOSANO. p.436 2007).

Esse enquadramento das relações de gênero tem profundas consequências nocivas às mulheres. Além de serem excluídas do âmbito público, no doméstico o entendimento de que há uma inferioridade da mulher em relação ao homem e sua capacidade limitada no direito de família pode, por exemplo, até mesmo sancionar a violência doméstica, que é capaz de ser considerada como uma forma de ta'dib, correção (MÁRIO LOSANO, 2007; PNUD, 2016).

O relatório de desenvolvimento humano no mundo árabe do Programa das Nações Unidas para o Desenvolvimento (PNUD) (2016) reafirma que na região, há barreiras jurídicas para a igualdade de gênero. Acrescenta que as leis relacionadas à família acabam sendo uma fonte central de desigualdade simbólica e material ao realçar as desigualdades e ao limitar o direito das mulheres de se casar, divorciar-se, obter a guarda dos filhos e herdar.

0 documento ressalta também que em um contexto no qual religião e jurisdição estão interligadas, o viés patriarcal incorporado pelos códigos e legitimado pelas instituições religiosas é de difícil contestação. Ademais, o PNUD afirma que os códigos penais são geralmente - indulgentes para os que cometem crimes de violência contra as mulheres, especialmente a conjugal, estupro e os chamados crimes de honra.

Além disso, a Fiqh, jurisprudência, que em teoria deveria refletir a Sharia, na realidade, é tomada pelas interpretações patriarcais dos teólogos juristas (PNUD, 2016). Azizah Al-Hibri (1998) afirma que essas perspectivas jurídicas derivam mais dos padrões sociais machistas que dos princípios do Alcorão, cujo entendimento por parte dos peritos em fiqh é influenciado pelos preconceitos sociais.

Por outro lado, a lei é lida dentro de uma conjuntura política social, logo a interpretação dos direitos torna-se sujeita ao paradigma social dominante, o de um mundo engendrado, socialmente construído, misógino e onde as experiências das mulheres são raramente reconhecidas (NATALIE KAUFMAN;STEFANIE LINDQUIST. p.106. 1995). Portanto, entendimentos dos direitos das mulheres na Sharia são influenciados por perspectivas culturais que as veem com capacidades limitadas e busca a manutenção de seu papel na família (MAHNAZ AFKHAMI. p.9 1995). 
Além disso, esse viés na interpretação dos textos islâmicos combinado à segregação cultural e à social, e o monopólio de um grupo de teólogos homens sobre a interpretação dos textos religiosos resulta em violência contra as mulheres bem como a supressão dos direitos delas (MAHNAZ AFKHAMI. p.9 1995). Fatima Mernissi (1991 apud SIDANI, 2005) afirma que há grupos interessados em bloquear os direitos femininos nas sociedades muçulmanas de modo que a tentativa de controle das mulheres e seu poder é até mesmo institucionalizada.

Se os direitos das mulheres são um problema para alguns muçulmanos modernos, não é nem por causa do Alcorão nem do Profeta, nem da tradição islâmica, mas simplesmente porque esses direitos conflitam com os interesses de uma elite masculina (MERNISSI, 1991 p.9 apud SIDANI 2005 p.506)

Além de Fatima Mernissi, autoras como Eleanor Abdella Doumato (1995) e Ann Mayer (1995) afirmam que a Sharia, mesmo que não ofereça um standard significativo para apoio dos Direitos Humanos pode ser usada para restringir bem como expandir os direitos das mulheres dependendo das condições da sociedade e interesses da elite política. Acreditam que o texto tem uma certa ambiguidade e flexibilidade que permite que visões políticas e sociais opostas sejam validadas com referência ao mesmo corpo de direito.

Desse modo, muitas violações dos Direitos Humanos das mulheres, a violência contra elas e a subordinação são justificadas, por essas elites, por referência à cultura, religião ou tradição quando na verdade devem ser entendidas como uma realidade política e socialmente construída (CHARLOTTE BUNCH. p.491, 1990, SUSAN OKIN. p.35, 1998). A influência crescente desse tipo de justificativas no mundo muçulmano é uma razão pela qual é tão importante que os direitos das mulheres sejam completamente reconhecidos como Direitos Humanos (CHARLOTTE BUNCH. p.491. 1990).

\section{Aspecto Cultural}

É fato que não existe uma cultura que não seja mediada por múltiplos eixos de desigualdades, estas que por vezes são consideradas insignificantes ou culturalmente apropriadas (CAROLE NAGENGAST p.5. 1998). Nesse sentido, a subordinação feminina é tão profunda que ainda é vista como inevitável ou natural, e não como uma realidade politicamente construída, mantida por interesses, ideias e instituições patriarcais (CHARLOTTE BUNCH. p.490.1990).

Entretanto, mesmo que o machismo e suas consequências sejam universais, apresentam diferentes facetas, isso deve ser levado em consideração. A noção de um patriarcado que assume as mesmas formas universalmente fracassa em explicar os mecanismos de opressão de gênero nos diferentes contextos que existem (JUDITH BUTLER. p.32. 2016). E ainda se ressalta que essas variedades resultam em diferentes demandas que nem sempre são respondidas pelos Direitos Humanos e sua busca pela generalização. 
Com isso em mente, percebe-se que as mulheres muçulmanas, em geral, são afetadas por leis e costumes que frequentemente contribuem para o menor poder delas em suas famílias bem como no âmbito público (SUSAN OKIN. p.36 1998). Distinções e normas de pontos relacionados à sexualidade, à herança, ao casamento, ao divórcio, à guarda dos filhos e à vida doméstica como um todo são justificados como estando de acordo com aspectos culturais e religiosos. Assuntos que têm um peso muito maior na vida da mulher do que dos homens (FARIDA SHAHEED. p.1002. 1994).

Nesse contexto, o conceito de relatividade cultural, desenvolvido pelos antropólogos para induzir o respeito pela diferença, é apropriado, simplificado e utilizado por Estados ou grupos despóticos patriarcais para racionalizar e desculpar os abusos dos Direitos Humanos (NAGENGAST. p.9. 1998) que assim são justificados sobre o "manto legitimador do relativismo cultural" (ALVES, 2013 p. 343). Assim, o recurso da cultura como um baluarte contra as liberdades ocidentais, caracterizadas como nocivas, fornece uma justificativa conveniente para a relutância dos governos em cumprir com a lei internacional de Direitos Humanos (MAYER. p.70. 2007).

Documentos voltados para os direitos das mulheres, como a CEDAW (1979) e Declaração e Plataforma de Ação de Pequim (1995) foram assinados e até mesmo ratificados por governos de países cujas leis ou práticas aceitas estavam longe de cumprir as disposições destas (OKIN. p.37. 1998). No Mali, por exemplo, país que assinou e ratificou ambas, em 2012, 91\% das mulheres entre 15 e 49 anos haviam sido submetidas a algum tipo de mutilação genital (UNFPA, 2012).

Outro problema são as reservas feitas, a CEDAW, por exemplo, foi o instrumento que recebeu maior número de ressalvas por parte dos Estados dentre os tratados internacionais de Direitos Humanos. Parte significativa dessas reservas focavam no princípio de igualdade entre homens e mulheres alegando argumentos culturais e religiosos; países como Bangladesh e Egito acusaram o comitê de praticar um imperialismo cultural (FLÁVIA PIOVESAN. p. 25. 2011).

Entre os Estados árabes todos - menos Somália e Sudão - assinaram, todavia, as reservas dos que o fizeram foram tantas que minou sua importância e validade na região (PNUD, 2016). Na conferência de Viena em 1993, China, Malásia e Síria usaram noções de integridade cultural para criticar vários aspectos da doutrina de Direitos Humanos e também alegaram uma tentativa de estabelecimento de hegemonia cultural pelo ocidente (ARATI RAO. p.112.1995).

Perpetua-se assim, uma falsa dicotomia na qual barreiras geopolíticas são apagadas e uma variedade de culturas são colocadas em dois pacotes, cada um sendo internamente consistente e monolítico, mas em discordância com o outro e um com o selo de Direitos Humanos e outro não (RAO, 1995 p.115; NARAYAN p.96 1998). Esse argumento, portanto, também falha ao totalizar a cultura, fazer acreditar que há uma única, dominante e uniforme cultura em toda sociedade e que não é passível a mudanças (MAYER. p.313. 1994). 
Ao apresentar um discurso generalizante e de uniformidade cultural, desconsiderando evidências empíricas de diversidade ignoram que:

\footnotetext{
A cultura não é uma coisa, mas sim um conjunto de práticas historicamente e socialmente situadas, nunca inertes ou estáticas, mas um produto sempre fragmentado e mutante de negociação e luta. Como tal, essas práticas estão sujeitas a renegociação como resultado de novas lutas" (NAGENGAST, 1998 p.7, tradução nossa).
}

A cultura é uma série de práticas sociais constantemente contestadas e negociadas, cujos significados são influenciados pelo poder e status de seus interpretadores e participantes (RAO p.113. 1995). Noções essencialistas de cultura, em geral, mostram-na como dados imutáveis, ignorando as mudanças históricas e o papel de contestações políticas e sociais. Isso promove a imagem da cultura como algo estático, como se seus valores, práticas, tradições e senso do que deve ser preservado fosse imune à história (NARAYAN. p.98 1998).

Assim, na maioria das sociedades muçulmanas, a articulação cultural do patriarcado através de estruturas, costumes sociais, leis e poder político é justificada por referência à doutrina religiosa. Esta tarefa é facilitada pelo papel central do Islã na autodefinição identitária e da realidade cultural dos muçulmanos (FARIDA SHAHEED. p.999. 1994).

Nesse contexto, as mulheres são tidas como guardiãs da cultura e das tradições, por meio de roupas obrigatórias, comportamento esperado, bem como legislação que, no discurso, pretende protegê-las, elas são designadas como repositórios de significados culturais (NAGENGAST p.9, 1998; SHAHEED. p.1001. 1994). Ironicamente, essas normas culturais das quais elas são as protetoras são as que implicam no confinamento à esfera doméstica e status de segunda classe (NAGENGAST. p.13.1998).

A cultura e até mesmo o enfoque nos direitos civis e políticos reforçam a separação das esferas pública e privada, geralmente operando em detrimento das mulheres (CHARLESWORTH p.53, 1994; TICKNER. p.33. 2001). Assim essa dicotomia além de reforçar as relações de poder, é usada para justificar a subordinação feminina no lar e excluí-las das esferas nas quais decisões são tomadas (BUNCH. p.493.,1990; CHARLESWORTH. p.53. 1994).

A questão de justificativas culturais já foi tratada no âmbito internacional. A CEDAW se posiciona sobre o papel que as tradições, estereótipos e preconceitos exercem sobre a restrição dos direitos e das liberdades fundamentais da mulher em seu artigo quinto. Este afirma que medidas, mesmo especiais de caráter temporário, devem ser tomadas pelos Estados parte para acelerar e incentivar a eliminação de práticas culturais e comportamentos estereotipados que discriminem as mulheres ou as coloquem em situação de desvantagem (ONU,1979).

Na década de 1990, o tema continuou a ser tratado tanto no âmbito global quanto regional, como exemplo deste último está a Convenção para Prevenir, Punir e Erradicar a Violência Contra a Mulher ou Convenção de Belém do Pará de 1994. Esta prevê a garantia de educação livre de padrões e costumes sociais estereotipados baseados na inferioridade 
e subordinação feminina e assim "busca alterar a estrutura patriarcal da sociedade incentivando mudanças culturais." (LAURA MATTAR, TAMARA GONÇALVES, 2008 p. 1348).

A Declaração e Plataforma de Ação da IV Conferência Mundial Sobre a Mulher de Pequim em 1995 rejeitou - veementemente - justificativas culturais para a não observância dos Direitos Humanos das mulheres. Outrossim, reconheceu a importância dos valores culturais mas ressaltou a necessidade de eliminação de aspectos nocivos de práticas tradicionais que violam os direitos das mulheres, além de reconhecer que é dever dos Estados proteger os Direitos Humanos e liberdades individuais (ONU, 1995).

A Recomendação Geral número 21 do comitê da CEDAW de 1994 afirmou que o Estado deve desencorajar toda noção de desigualdade entre a mulher e o homem, seja afirmada por leis, pela religião ou pela cultura (PIOVESAN. p. 152 2011). A Declaração e Programa de Ação de Viena de 1993 chamou os Estados a erradicar qualquer divergência entre os direitos da mulher "e consequências nocivas de determinadas práticas tradicionais ou costumeiras, do preconceito cultural e do extremismo religioso" (ONU, 1993, p. 17).

Nesse sentido, é interessante indagar quem decide quais práticas são nocivas ou não e se os Estados cujo dever é proteger seus cidadãos estão dispostos a tal. É necessário, portanto, um olhar sobre o contexto geral político, social e econômico em que violações ocorrem e assim entender quais interesses são servidos por tradições e costumes que controlam a autonomia das mulheres e quem se beneficia desses princípios culturais (CAROLE NAGENGAST. p15. 1998).

Forjar identidades culturais nacionais é uma prática frequentemente explorada por aqueles que estão no poder, em geral homens, com o objetivo de promover seus interesses e manter o status quo. Tal fato é usado pelas elites domésticas para esconder divisões e manter controle nacional (TICKNER, 2001; SHAHEED. p.1005. 1994). Carole Nagengast (1998) aponta o quão suspeitas são as demandas de relatividade cultural que vêm de políticos cuja própria existência depende da aprovação de seus próprios governos ou das elites patriarcais que se beneficiam da contínua opressão das mulheres.

Uma Narayan (1998) usa o termo selective labeling para designar o fato que os grupos dominantes designam certas mudanças de costumes como perda cultural ou traição cultural enquanto outras mudanças de práticas estão de acordo com a preservação cultural. Essa "rotulagem seletiva" (NARAYAN, 1998, p. 89, tradução nossa) tem um papel importante na manutenção da conjuntura ao retratar as mudanças que ameaçam o status quo como nocivas à cultura.

A opressão das mulheres também é política (BUNCH. p.495.1990), "a sharia é o escudo atrás do qual governantes e líderes fundamentalistas corroboram para restringir o impulso feminino por liberdade e igualdade" (AFKHAMI, 1995, p. 10, tradução nossa). “O próprio conceito de feminilidade muçulmana é uma fórmula muito potente para a manutenção do status quo, pois implicitamente ameaça as desafiantes com ostracismo" (FARIDA SHAHEED, 1994, p. 1005). 
Quando as relações de gênero são vistas como essenciais à cultura, as mulheres que se desviam da definição e das normas são punidas, moral ou fisicamente, isso pode ser usado como modo de legitimar o controle e opressão das mulheres bem como solidificar as identidades pretendidas como homogêneas. Essa realidade mostra-se um terrível fato no contexto de grupos fundamentalistas (TICKNER. p.18. 2001).

Para grupos radicalistas islâmicos, mulheres também são as protetoras da cultura contra o Ocidente; logo, liberdade e igualdade de gênero são frequentemente vistos como símbolos claros de valores ocidentais, que portanto devem ser rechaçados por estarem em contraste com o conservadorismo por eles pregado (OKIN. p.36 1998). Ao ressaltar a contradição, Uma Narayan (1998) aponta que enquanto grupos como o Talibã almejam a volta das mulheres aos lares, afirmando que estão sendo contaminadas pelo Ocidente, eles não têm problemas em comprar armamentos de origem ocidental.

Nesse contexto, o que falta às mulheres é o poder da escolha e ter alternativas. Deve-se indagar se elas têm o direito de resistir às práticas culturais que as privam dos direitos de que gozam os homens ou que lhes causam danos psicológicos ou corporais. Ou também até que ponto as mulheres tiveram palavra a dizer na formulação e perpetuação de regras e costumes culturais que as rebaixam ou lhes conferem menos vantagens que os homens (NAGENGAST. p.15. 1998).

Muitas vezes, a autonomia a elas é negada. Não obstante, o papel da mulher é pré-determinado pela sociedade, relações familiares e religiosas, haja vista que elas têm uma função prevalente. Entretanto, se os indivíduos não são livres para escolher se estão dentro ou fora da coletividade, não estão livres para apoiar ou se opor aos seus ditames, então a noção de direitos de grupo torna-se vaga (NAGENGAST. p.11 1998). Não é somente assegurar os direitos mas também garantir a possibilidade de manifestação, de ter a opção de escolha e ter influência sobre sua própria realidade.

Esse "chauvinismo masculino das sociedades patriarcais muçulmanas e dos Estados neopatriarcais" (MONSHIPOURI, 2004, p. 23) não é o único problema que elas enfrentam. Ao comentar sobre esses e outros desafios Mahmood Monshipouri (2004), afirma que elas ainda têm que lutar contra os radicais e os tradicionalistas islâmicos.

\section{Fundamentalismo}

0 extremismo, em todas as suas formas, tem sérios efeitos sobre os direitos de mulheres e meninas, as violações, que muitas delas enfrentam nesses contextos vão de casamento forçado, restrições à educação, ao trabalho e à participação na vida pública além de sistemática violência de gênero (ONU MULHERES, 2015). Mário Losano (2007), ao falar do caso muçulmano, afirma que os fundamentalistas vão além da interpretação restritiva do Alcorão, gerando assim, total segregação feminina. 
Fundamentalistas islâmicos tradicionalistas e radicais criticam certas mudanças sociais, entre elas, a igualdade de gênero. Eles as enxergam como grandes ameaças aos valores, arranjos e segregações tidos como culturais, seja no âmbito familiar ou da sociedade (MONSHPOURI. p.211. 2004). "A relativa melhora de posição das mulheres é vista pelas forças conservadoras como um fator potencialmente forte para destruir a família patriarcal e sua estrutura demográfica, econômica e política (MOGHADAM, 2003, p. 136 apud MONSHPOURI, 2004, p. 209).

Assim, qualquer exigência por Direitos Humanos seria tratada por esses grupos como uma tentativa de ocidentalização e, portanto, um risco. Desse modo, fomentam a segregação, obrigam o uso de certas vestimentas e a observância religiosa, a modéstia e ideias como a de que o testemunho de um homem equivale ao de duas mulheres. Há a tentativa de controle de todos os âmbitos da vida feminina, incluindo circulação, sexualidade e reprodução, limitando assim, liberdades fundamentais (MONSHPOURI p.211. 2004).

A plataforma de Pequim já havia tratado sobre esse tema, abordando a religião de forma menos abstrata e também mais crítica. Esta afirma o papel da espiritualidade e crença na vida de milhões de pessoas, mas acrescenta que qualquer forma extremista pode ter impacto nocivo, levando à discriminação e à violência (ONU, 1995, OKIN p.35, 1998). É significativo que em um documento como este as religiões sejam vistas com outra perspectiva, principalmente do ponto de vista das mulheres que buscam direitos (OKIN p.35. 1998).

A ascensão desse tipo de fundamentalismo, com base religiosa, resultou em duas tendências opostas; por um lado a intensificação da subordinação feminina e por outro o surgimento de uma reação, reivindicando, principalmente, direitos (MONSHPOURI. p.189. 2004). E esse ativismo trouxe resultados, a adoção da resolução 1352 do Conselho de Segurança da ONU marcou o começo da Agenda sobre Mulheres, Paz e Segurança (ONU MULHERES, 2015).

O documento reconhece o impacto dos conflitos sobre as Mulheres e seus Direitos Humanos e urge ao Secretário-Geral e aos Estados a adotarem uma perspectiva de gênero em suas missões e no processo de paz. Além disso, invoca todas as partes envolvidas em conflito armado a respeitar plenamente o direito internacional aplicável aos direitos e à proteção de mulheres e meninas (ONU, 2000).

Desde então, o quadro normativo para a proteção e promoção dos direitos das mulheres em contextos de conflito e pós-conflito expandiu-se, mais quatro resoluções foram adotas no Conselho de Segurança. A maior parte do crescimento da Estrutura Normativa sobre Mulheres, Paz e Segurança concentrou-se nas obrigações, de organizações e Estados, relacionadas à proteção das mulheres em contextos de guerra (ONU MULHERES, 2015).

Percebe-se que, nesses contextos, esforços antiterrorismo que consideram o problema exclusivamente a partir da perspectiva securitária, aumentam as inseguranças dessas mulheres. Situações de crises, como nas quais esses grupos surgem e se estabelecem, exacerbam a discriminação existente contra mulheres e dificultam o desfrute de seus direitos 
fundamentais, como o à saúde, à educação, à alimentação, à proteção e à integridade física (ONU MULHERES, 2015).

Na Assembleia Geral foi apresentado, pelo comitê de Direitos Humanos, um relatório que insta aos governos a corrigir a desigualdade de gênero que faz com que as mulheres sejam alvos dos fundamentalistas. Também urge que aqueles garantam que as vítimas recebam apoio, inclusive por meio da remoção de barreiras discriminatórias que frustram a assistência e impedem que mulheres reclamem seus Direitos Humanos, como por exemplo, leis desiguais (ONU MULHERES, 2015).

Por consequência, as resoluções da Assembleia Geral sobre a proteção dos Direitos Humanos e liberdades fundamentais na luta contra o terrorismo demandam a formulação, exame e implementação de medidas para combater o terrorismo que estejam de acordo com os princípios da igualdade de gênero e da não discriminação (ONU MULHERES, 2015).

Sobre o tema, no âmbito da CEDAW, o instrumento era criticado por não tocar no tema da violência e nem dos direitos das mulheres em contextos de contenciosos armados, em 2013 foi adotada a recomendação geral número 30. Esta insta aos Estados partes a assegurar o cumprimento das obrigações decorrentes da convenção antes, durante e após um conflito. Também pede que os governos rechacem qualquer retirada da proteção ou direitos da mulher por grupos não estatais, como terroristas (ONU MULHERES, 2015).

Um dos exemplos para esse contexto vem do Afeganistão a partir da década de 1990, onde o Talibã, em sua busca por uma sociedade regrada completamente pelas normas fundamentalistas, exilou as mulheres da vida pública, banindo-as de escolas e do trabalho assalariado (AL-HIBRI. p.65. 1998; NAGENGAST. p.17. 1998). Essa segregação também foi exacerbada pelo fato de que elas só podiam sair de casa estando completamente cobertas e acompanhadas por um parente do sexo masculino (NAGENGAST. p.14. 1998).

As mulheres ficaram essencialmente invisíveis na vida social e política, presas em casa e negadas de seus direitos. As consequências para o descumprimento dessas regras incluem prisões, espancamentos e até apedrejamentos (ANISTIA INTERNACIONAL, 2014). Em contextos como esses, o gênero é um eixo que se cruza com outras identidades e experiências, formando as perspectivas do que é ser mulher em realidades nas quais grupos fundamentalistas dominam (ONU MULHERES, 2015).

\section{O Feminismo Muçulmano}

É importante analisar o papel do ativismo nos Direitos Humanos pois o desafio do fundamento destes não é resolvido apenas por declarações em âmbito estatal, esse obstáculo é também histórico-social (GALLARDO. p.273 2013). Está ligado a reivindicações, de modo que a base dos Direitos Humanos tem como motor a luta social. Nesse sentido, ter êxito é superar limitações sociais e materializar essas lutas em "instituições e lógicas sociais sancionadas juridicamente" (GALLARDO, 2013, p. 271). 
No entanto, a luta não está apenas no fundamento, continua também uma vez que esses direitos já foram positivados, representando um embate entre poderes e liberdades (FERRAJOLI, 1995 apud GALLARDO. p.275 2013). Ou seja, a norma jurídica sem a legitimação social das conquistas e das lutas é ineficaz (GALLARDO p.275 2013). Essa contestação do Estado como lugar da positivação jurídica está relacionada à resistência, um questionamento da legitimidade que converge para o centro, dando lugar a um modelo que faz o movimento inverso, voltado para o particularismo de temas específicos (LAFER p.187. 2015).

Sobre o tema, Norberto Bobbio (2004) distingue a resistência da contestação. A primeira são ações de ruptura da ordem constituída, já a segunda uma atitude crítica que atinge também os modelos culturais gerais que asseguram legitimidade ao sistema político vigente. Por isso, reafirma-se que a fundamentação dos Direitos Humanos está ligada a reivindicações de movimentos sociais. (GALLARDO p.271. 2013).

As mulheres muçulmanas, ao contrário da representação estereotipada que as mostra em sua totalidade como vítimas passivas, estão negociando e contestando sistemas de poder de maneiras diversas e transformadoras em seus países (PNUD, 2016). Elas transmitem suas ideias, necessidades e aspirações em uma ampla variedade de campos, concordando sobre a necessidade de mudar suas sociedades e melhorar as relações de gênero (SIDANI p.505. 2005).

Não se pretende aqui afirmar que o feminismo islâmico é um único bloco homogêneo. As lutas do grupo de mulheres em questão incluem várias facetas e se dão em diferentes contextos e de variadas formas. Haifaa Jawad (2003) afirma que algumas mulheres engajadas no ativismo rejeitam o termo feminismo, por enxergá-lo como uma categoria predominantemente Ocidental. Ressalta-se também que as demandas dessas mulheres são diversas.

Tais demandas incluem exemplos de movimentos que se concentram em desafiar as leis de tutela masculina, como os marroquinos que conseguiram aumentar para 18 anos a idade mínima para casamento de mulheres (PNUD, 2016). Mudanças como essas, seja na estrutura da família seja na ampliação de temas do ativismo, são sinais de questionamento do patriarcado, isso gera uma reação conservadora ao provar que elas estão se tornando cada vez mais atrizes sociais (SHAHEED. p.1002. 1994; PNUD, 2016).

Outro exemplo notável é a organização Women Living Under Muslim Laws fundada em 1984, é um espaço de compartilhamento de experiências na promoção dos Direitos Humanos das mulheres, "uma rede feminista transnacional [...] espaço coletivo para mulheres cujas vidas são moldadas, condicionadas ou governadas por leis e costumes que dizem derivar do Islã." (WLUML, 2020 tradução nossa). Redes como essa conectam mulheres de diferentes países com agendas comuns, como direitos, saúde e reprodução (MONSHIPOURI. p.193. 2004).

Assim, conceitos, reivindicações e plataformas de ação de caráter feminista se tornam transnacionais, promovendo debates e trocas de experiências (LIMA p.168 2017). Isso é importante porque, para que os Direitos Humanos sejam mais representativos, é 
preciso que diferenças entre as mulheres sejam ouvidas e teorizadas, que a estratégia de avanço feminista contenha a contribuição de variadas vozes e experiências (NARAYAN p.89 1998).

Em geral, as campanhas e o ativismo focam principalmente nos direitos das mulheres e na igualdade de gênero, abordando questões como reformas dos códigos de status pessoal e penais, representação política e violência baseada em gênero (PNUD, 2016). Assim, esse movimento de trocas também é essencial para compreender as diferentes realidades sociopolíticas das mulheres na região e como suas batalhas por igualdade também são feitas de modo a relacionar os aspectos de suas realidades e os Direitos Humanos (LIMA p.58. 2017; MAYER. p.72. 2007).

E, além de dialogarem entre si, mulheres muçulmanas também debatem narrativas do feminismo mais geral no sentido de trazer as conquistas alcançadas no plano internacional para as realidades locais. Combinam abordagens religiosas com um quadro internacional de Direitos Humanos e modernidade, argumentando que estes são compatíveis (PNUD, 2016; LIMA p.58 2017). Desse modo, para elas, instrumentos internacionais são esforços válidos, mas atuam com a intenção de extrair das convenções as suas compreensões, reivindicando assim a aplicação dos direitos das mulheres ao Islã (LIMA p.105 2017).

Assim como os feminismos pós-coloniais como um todo, o islâmico, também chama atenção para a variedade de contextos de classes, culturas e históricos. Faz esse movimento de ressaltar suas complexidades conjunturais e estabelecer um diálogo com esse grupo mais amplo de modo a entender em quais aspectos é possível reconhecer similaridades (LIMA p.14 2017).

Nenhuma visão monolítica do ponto de vista e realidade da mulher podem ser assumidas, trocas entre os discursos feministas são cruciais para importar para o cenário internacional uma multiplicidade de questões que marcam a agenda em diferentes contextos nacionais (NARAYAN. p.87. 1998). Prover oportunidades para diálogo no qual mais vozes participem na definição dos critérios, atribuição de valores e adicionando contextos e experiências que vão guiar o movimento para os Direitos Humanos é essencial para o enriquecimento do discurso e sucesso do projeto, portanto do interesse de todas (AFKHAMI p.16 1995).

Então, fazer essa conexão também é importante para chamar a atenção daqueles que, baseados em estereótipos, tendem a deslegitimar os protestos políticos das muçulmanas. Rebatendo assim, argumentos de que conceitos como democracia, liberdade de expressão e tolerância religiosa são estranhas e contra os valores autênticos da cultura islâmica (AL-'AZM, 1989 apud MAYER. p.336. 1994).

Ao analisar o Orientalismo, Edward Said (2007) afirma que esse termo está repleto de dogmas que propõem e reforçam contrastes entre o Ocidente, visto como racional, desenvolvido e humanitário e o Oriente, tido como inferior, atrasado e estranho. Ainda segundo o autor, trata-se de um sistema estático que vê o objeto de estudo como uniforme 
e imutável, analisando-o a partir de abstrações que concebem uma civilização clássica em detrimento de evidências modernas e reais.

Esses estereótipos apagam qualquer vestígio de individualidade, de modo que "o homem oriental é primeiro oriental e depois homem" (SAID, 2007, p. 312), também se aplica às mulheres. 0 orientalismo, sendo campo exclusivamente masculino usa, portanto, uma ótica sexista, evidente na maneira que as mulheres são retratadas. Esse sistema de representações que as mostram muitas vezes exaltando sua sexualidade e as definindo coletivamente exclui qualquer narrativa que foge do padrão construído (SAID p.218. 2007).

Nesse contexto, mulheres muçulmanas têm o papel também de mostrar representações mais fidedignas, retratar as variedades culturais que existem entre elas e que são ignoradas ou mal concebidas pelo Ocidente (AFKHAMI p.14. 1995). Embora as experiências de mulheres nos países árabes tenham muito em comum, elas são afetadas por diferentes especificidades nos vários contextos políticos, jurídicos e econômicos. Essa diversidade de experiências precisa ser reconhecida, sem isso, ignora-se as complexas raízes, formas e resultados da luta de mulheres na região por seus direitos (PNUD, 2016).

Ressalta-se ainda que os movimentos de mulheres em questão são diversificados e se estendem desde a política tradicional ao ativismo informal e iniciativas culturais alternativas, tendo se expandido em termos de territoriais e de alcance popular (PNUD, 2016; LIMA p.14 2017). Entretanto, mesmo que não seja possível conceber o movimento como uma voz única, o padrão percebido de atuação é o de contestação das leis e dos códigos, propondo leituras religiosas alternativas e suas próprias visões (SIDANI, 2005; PNUD, 2016).

Busca-se, nesse viés, a emancipação a partir de uma perspectiva de reinterpretação e reforma do Islã. Grupos que adotam essa abordagem, concentram-se na transformação radical da jurisprudência islâmica e usam argumentos do próprio instrumental religioso para desafiar a desigualdade de gênero (LIMA p.14 2017). Promove-se, desse modo, uma reinterpretação das fontes textuais, provando que as desigualdades e subordinação não são provisões divinas, mas sim construções humanas (MIR-HOSSEINI p.632. 2006).

"Para o feminismo islâmico a ideologia e o poder patriarcal, que seriam externos ao Islã, são responsáveis pelas distorções nas leituras das fontes religiosas islâmicas" (LIMA, 2017, p. 72). Ou seja, as normas foram assimiladas na jurisprudência islâmica por meio de um conjunto de suposições e convicções dos seus intérpretes, como a da inferioridade feminina, e assim se refletem nessas construções desiguais (MIR-HOSSEINI p.635. 2006).

Acredita-se, portanto, que as interpretações patriarcais podem e devem ser desafiadas e que a sharia e fiqh necessitam ser distinguidas, respectivamente, em revelação e compreensão humana da palavra divina. Ressalta-se também que este último está sendo usado para legitimar as regras patriarcais sobre as relações familiares e de gênero na sociedade, criando uma barreira ao redor dessas construções machistas (MIR-HOSSEINI p.632. 2006; LIMA p.75 2017). 
Elas não apenas criticam o que veem como viés patriarcal, mas também emitem suas propostas para repensar a herança islâmica, abrindo portas para novas abordagens (MAYER. p.73 2007). Contribuições de mulheres destacam-se como tendo um potencial revolucionário para "descobrir uma história escondida" (MIR-HOSSEINI, 2006, p. 642 tradução nossa). Isso porque correntes feministas islâmicas encontram respaldo para suas demandas nas primeiras fontes islâmicas (MAYER. p.73. 2007).

As mulheres muçulmanas eram ativas e desempenharam um papel visível no nascimento da comunidade. Algumas feministas contemporâneas consideram que relembrar esses papéis históricos, estabelece um precedente interessante para a emancipação das mulheres (SIDANI p. 501. 2005). Afirmam também que os Direitos Humanos podem complementar essa versão original do Islã, que foi corrompida pelo viés machista (MAYER. p.68. 2007).

Fazem assim uma distinção entre o que é religioso e o que é tradição patriarcal, ressaltando que não é a cultura que está na raiz dos problemas enfrentados pelas mulheres. O problema, afirmam, é a falta e a proibição de educação sobre os conceitos de igualdade e acesso e experiência com o poder político e econômico (CAROLE NAGENGAST p.15. 1998; MONSHIPOURI 2004).

O feminismo islâmico fica no meio das contradições entre a visão ocidental e preconceituosa sobre o Islã e o âmbito nacionalista que vê o feminismo como projeto neocolonial. Nesse contexto, o caráter religioso do feminismo auxiliou ao trazer perspectivas mediadoras mais próximas da realidade dessas mulheres para o avanço do debate. Fornece também um leque de análises e narrativas que desconstroem a estrutura argumentativa determinista de submissão da mulher ao poder dos homens, estabelecido pelos discursos machistas das autoridades e juristas tradicionalistas (LIMA p.89, 2017).

No entanto, também existem críticas a esse tipo de abordagem, Valdecila Lima (2017) afirma que ela pode ter uma função limitadora. Isso porque, essa ótica dificulta pensar questões relacionadas ao gênero fora dos limites da religião, como, por exemplo, debater sobre a sexualidade de forma mais ampla, tema que o feminismo islâmico não trata abertamente. Também não permite, ressalta a autora, estabelecer críticas àquilo que é advindo da religião.

Outro grande obstáculo para a organização política das mulheres é o caráter antidemocrático de alguns regimes políticos que suprimem a dissidência e proíbem as organizações da sociedade civil e os encontros públicos. Uma resposta a essa questão pode ser o ativismo em plataformas on-line, ou então usar momento de protestos e clima de questionamento para promover a justiça de gênero como um elemento integral de uma justiça social mais ampla, como aconteceu no Egito em 2011 (PNUD, 2016).

\section{Considerações Finais}

Ao analisar os Direitos Humanos das mulheres a partir da problematização da forma como esses ainda permanecem no âmbito estatal e principiológico, constatou-se a 
necessidade de maior participação efetiva delas no processo de internalização bem como no cenário internacional, trazendo novas questões e pontos de vista.

É evidente que o referencial de Direitos Humanos, mesmo que tenha nascido muito generalista, foi se especificando conforme a necessidade de determinados grupos, como mulheres e crianças. Esse movimento, que pode ser comprovado por documentos como a CEDAW, foi de extrema importância. Por meio do ativismo, mulheres levaram suas demandas ao cenário internacional e mostraram a todos que os Direitos Humanos das mulheres e meninas devem ser um elemento ímpar e indivisível dos Direitos Humanos universais. Não era mais possível que metade da população mundial sofresse diariamente violações de seus direitos e nada fosse feito.

Entretanto, críticas de feministas de fora do norte global afirmavam que essa transformação acabava se mostrando insuficiente, pois especificidades de certos grupos de mulheres eram esquecidas em detrimento da ótica branca e ocidental. Ou seja, além de um generalismo na construção do referencial dos Direitos Humanos, que ignora as mulheres, há um também no próprio projeto de especificação.

De forma geral, a crítica era que a perspectiva de mulheres de países desenvolvidos foi apresenta como a única, como se todas vivessem em Estados democráticos e lidassem com os mesmos tipos de violações, por exemplo. Nesse contexto, muito do referencial não fazia sentido nem era eficaz na prática para parte das mulheres no mundo.

Isso porque, elas vivem diferentes realidades, sendo assim, suas demandas e a forma como esses direitos podem ser melhor internalizados são diversas. Portanto, mesmo que os Direitos Humanos sejam, em sua gênese, pautados por normas gerais e universais, para que eles sejam mais eficazes nos contextos locais é necessário levar em conta as diferentes especificidades.

Percebe-se então, a necessidade da abertura de um espaço de diálogo mais representativo, no qual diferentes pontos de vista de feministas de países emergentes, de mulheres LBT (lésbicas, bissexuais e transexuais), indígenas, negras entre outras, sejam incluídas no movimento global para os Direitos Humanos das mulheres. Acredita-se que, a partir dessa maior pluralidade de ideias e questões, os Direitos Humanos possam ter cada vez mais legitimidade e efetividade.

E nesse sentido, inclui-se as mulheres muçulmanas que, em geral, vivem uma notável condição de opressão justificada pela cultura e religião. No entanto, essa conjuntura não significa que elas estejam inertes frente a situação. Nas suas diferentes realidades, estão procurando maneiras para que os Direitos Humanos sejam respeitados, e ao revelar as estruturas misóginas que justificam tais violações, procuram formas para que o referencial existente seja útil para todas nessa comunidade.

Ademais, elas estão quebrando a ideia de que precisam de tutela e demandando serem ouvidas. Exemplos como Malala Yousafzai provam que escutar essas mulheres e outras ao redor do planeta é essencial para que o instrumental de Direitos Humanos responda às questões atuais e, assim, esteja sempre relevante frente aos temas contemporâneos. 
Acredita-se que, para esse movimento surtir efeito deve-se agir em duas frentes. Primeiramente a internacional, haja vista que mais mulheres, dos mais diversos grupos, nacionalidades e origens étnicas, têm que estar presentes pensando e trazendo novas demandas para os Direitos Humanos. Mesmo que grandes passos tenham sido dados nas últimas décadas, o sistema internacional, em geral, ainda é predominantemente masculino e engendrado e, nesse sentido, percebe-se que a baixa representatividade e pluralidade feminina pode enfraquecer o diálogo em Direitos Humanos e a criação de constantes debates.

Em segundo plano, nos Estados, as estruturas socioculturais devem ser levadas em conta, pois, mesmo com todo referencial existente, a desigualdade de gênero, patriarcalismo e o machismo ainda levam a uma situação de inferiorização das mulheres e consequentemente a violações de direitos. Entretanto, mesmo que esse seja um padrão global, as relações sociais que determinam a subordinação feminina se manifestam diversamente em cada contexto, exigindo construções que atendam as especificidades desses contextos para consolidação dos ideais internacionais.

E, muitas vezes, essas perspectivas patriarcais estão embutidas nos próprios Estados, aqueles que deveriam ser os responsáveis pela internalização desse instrumental de direitos. Sendo assim, é imprescindível a participação das mulheres também no processo de trazer o que foi pensado em nível internacional para os âmbitos locais. Elas que devem ditar de que forma esse referencial pode melhor se encaixar na realidade, seja por intermédio de ativismo, auxiliando no desenvolvimento de políticas públicas seja instigando debates nas diferentes esferas da sociedade, por exemplo.

Não é possível esperar que uma concepção genérica e internacional funcione para lutar contra violações nos mais diversos contextos, deve-se levar em conta a ótica local. É necessário que haja a participação das pessoas afetadas, no caso as mulheres, para que esses instrumentos internacionais saiam da lógica principiológica.

Deve-se agir, portanto, no sentido de permitir que as mulheres falem, uma vez que são elas que conhecem suas questões e demandas, logo, não é possível que outros se expressem por elas, como uma espécie de tutela, ou então, que suas reivindicações sejam esquecidas, e seus direitos permaneçam no papel e no âmbito dos Estados. Estes que já mostraram-se por vezes inertes frente a situações de violações e estar embebidos em ideias machistas presentes nas sociedades.

\section{Referências Bibliográficas}

AFKHAMI, Mahnaz. Introduction. In: AFKHAMI, Mahnaz. (Org.).Faith and Freedom: Women`s human rights in the muslim world. Nova York: Syracuse University Press,1995. p. 5-17 AL-HIBRI, Azizah. Legal Reform: Reviewing Human Rights in the Muslim World. Harvard International Review. v.50, n.20, p.56-68, jul/set. 1998. Disponível em: <https://scholarship. 
richmond.edu/cgi/viewcontent.cgi?referer=https://www.google.com.br/\&httpsredir=1\&article=1159\&context=law-faculty-publications $>$. Acesso em: 2 nov. 2018

BARATTO, Márcia. Direitos Humanos e diálogo intercultural: Possibilidades e limites. 2009. 160p. Dissertação (Mestrado em Ciência Política)- Instituto de Filosofia e Ciências Humanas. Universidade Estadual de Campinas, Campinas, 2009.

BOBBIO, Noberto. A Era dos Direitos. Rio de Janeiro: Elsevier, 2004 p.12-57

BUNCH, Charlotte. Women`s rights as human rights: Toward a Re-Vision of Human Rights. In: Human Rights Quarterly v.12 Baltimore: Jonhs Hopkins University Press. 1990 p.486.498 Disponível em:< https://www.jstor.org/stable/762496?read-now=1\&refreqid=excelsior\%3Ad084ed95ed29dadaf98fa7d36c0dc16b\&seq=1\#page_scan_tab_contents $>$. Acesso em: 5 maio. 2018.

BUNCH, Charlotte. Transforming human Rights from a feminist Perspective. in PETERS, Julie; Wolper, Andrea (Org.). Women`s Rights. Human Rigths: International Feminist Perspectives. Londres: Routledge,1995. p.11-16

BUTLER, Judith. Problemas de gênero: feminismo e subversão da identidade.11. ed. Rio de Janeiro: Civilização brasileira, 2016. p.17-37

CHARLESWORTH, Hilary. What are women's international human rights? In Human rights of women: National and international perspectives, In:. Cook, Rebecca(Org.). Human rights of women: National and international perspectives. Filadélfia: University of Pennsylvania Press. 1994. p.52-84 Disponível em:<https://trove.nla.gov.au/work/30358935?selectedversion=NBD11001037>. Acesso em: 12 out. 2018

CHARLESWORTH, Hilary. Human Rights as Men`s Rights in PETERS, Julie; Wolper, Andrea (Org.). Women`s Rights. Human Rigths: International Feminist Perspectives. Londres: Routledge,1995. p.103-114

DOUMATO.Eleanor Abdella. The ambiguity of Sharia and the politics of rights in Saudi Arabia- In:. AFKHAMI, Mahnaz (Org.).Faith and Freedom: Women`s human rights in the muslim world. Nova York: Syracuse University Press,1995. p. 135-167

GALLARDO, Hélio. Teoria crítica: matrizes e possibilidades de Direitos Humanos. 1.ed.São Paulo: Editora UNESP, 2013. p. 231-265

JAWAD, Haifaa. Muslim Feminism: A Case Study of Amina Wadud's “Qur'an and Woman. In: Islamic Studies v.42 Islamabad: Islamic Research Institute, International Islamic University. 2003 p.107.125 Disponível em:< https://www.jstor.org/stable/20837253?read-now=1\&refreqid=excelsior\%3A4d24231aa6dce3197abab871787ed7b6\&seq=5\#page_scan_tab_contents>. Acesso em: 19 mar. 2020.

KAUFMAN, Natalie; LINDQUIST, Stefanie.Critiquing Gender-Neutral Treaty Language: The Convention on the Elimination of All Forms of Discrimination Against Women in PETERS, Julie; Wolper, Andrea (Org.). Women`s Rights. Human Rigths: International Feminist Perspectives. Londres: Routledge,1995. p.103-114 
LAFER, Celso. A Reconstrução dos Direitos Humanos: Um Diálogo com o Pensamento de Hannah Arendt. São Paulo. Companhia das letras. p.163-198

LIMA, Cila. Feminismo islâmico: mediações discursivas e limites práticos. 2017. 235p. Tese (Doutorado)- Faculdade de filosofia, letras e ciências humanas da Universidade de São Paulo, São Paulo, 2017.

LOSANO, Mário. Os grandes sistemas jurídicos: Introdução aos sistemas jurídicos europeus e extra europeus. São Paulo: Editora Martins Fontes, 2007. p.399-459

MATTAR, Laura; GONÇALVES, Tamara. Convenção interamericana para prevenir, punir e erradicar a violência contra a mulher (1994). Convenção Belém do Pará. In: PIOVESAN, Flávia (Org.). Código de direito internacional dos Direitos Humanos anotado. São Paulo: DPJ editora, 2008. p. 1339-1350

MAYER, Ann Elizabeth. Universal versus islamic human rights: a clash of cultures or a clash with a construct?.Michigan Journal of International Law, Michigan, v. 12 n.2, p. $307-$ 404, jan./mar. 1994. Disponível em: < https://repository.law.umich.edu/cgi/viewcontent. cgi? referer $=\&$ httpsredir $=1 \&$ article $=1562 \&$ context $=$ mjil $>$. Acesso em: 17 out. 2018

MAYER, Ann Elizabeth. Rhetorical Strategies and official policies on Women`s Rights: The merits and Drawbacks of the new world hypocrisy. In:. AFKHAMI, Mahnaz (Org.).Faith and Freedom: Women`s human rights in the muslim world. Nova York: Syracuse University Press,1995. p. 104-133

MAYER, Ann Elizabeth. The Islam and Human Rights Nexus: Shifting Dimensions. Muslim World Journal of Human Rights. Pennsylvania, v. 4, n. 1, jan/mar 2007. Disponível em: < http://islamlawandwar.insct.org/wp-content/uploads/2014/06/Mayer_Islam_and_Human_ Rights_Nexus__Shifting_Dimensions.2007.pdf >. Acesso em: 17 out. 2018

MIR-HOSSEINI, Ziba. Muslim Women's Quest for Equality: Between Islamic Law and Feminism. Critical Inquiry. Chicago. v. 32, n. 4 p.629-645. jul./set. 2006 Disponível em: < https:// www.jstor.org/stable/10.1086/508085>. Acesso em: 15 nov. 2018

MOJAB, Shahrzad. Theorizing the Politics of Islamic Feminism. Feminist Review, v.81, n.69. p.124-146, dez./mar. 2001. Disponível em: < https://www.jstor.org/stable/1395633?seq=1\#page_scan_tab_contents $>$. Acesso em: 20 out. 2018

MONSHIPOURI, Mahmood. O Mundo Muçulmano em uma Era Global: A Proteção dos Direitos das Mulheres. Revista Contexto Internacional. Rio de Janeiro, v.26, n 1, jan./jun. 2004, p.187-217. Disponível em: < http://contextointernacional.iri.puc-rio.br/media/Monshipouri_vol26n1.pdf Acesso em: 27 out. 2018

MUTAHHARI, Mutadã. Os Direitos das mulheres no Islã. Lisboa: Editora ADFA, 1998. p.107-174

NAGENGAST Carole. Women, Individual Rights and Cultural Relativity: Power and Difference in Human Rights Debates. Women and International Development, Michigan, set./dez 1998 Disponível em: <http://citeseerx.ist.psu.edu/viewdoc/download?doi=10.1.1.195.5494\&rep=rep1\&type=pdf >. Acesso em: 17 out. 2018 
NARAYAN, Uma. Essence of Culture and a Sense of History: A Feminist Critique of Cultural Essentialism. Hypatia, Nova Jersey, v.13, n. 2, p. 86-106, mar/ jun. 1998 Disponível em: < http://www.jstor.org/stable/3810639 >. Acesso em: 7 out. 2018

OKIN, Susan M., Feminism, Women's Human Rights, and Cultural Differences. Hypatia, São Francisco, v. 13, n. 2, p.32-52, mar./jun. 1998. Disponível em < http://library.pcw.gov.ph/ sites/default/files/feminism,\%20womens\%20human\%20rights\%20and\%20cultural\%20 differences.pdf > Acesso em: 14 maio 2017

ONU. ORGANIZAÇÃO DAS NAÇÕES UNIDAS. Assembleia Geral. Declaração Universal dos Direitos Humanos. 1948. Disponível em: <https://www.ohchr.org/EN/UDHR/Documents/ UDHR_Translations/por.pdf>. Acesso em: 14 jun. 2018

ONU. ORGANIZAÇÃO DAS NAÇÕES UNIDAS. Assembléia Geral. Convenção Sobre A Eliminação De Todas As Formas De Discriminação Contra A Mulher. 1979 Disponível em: < http://www. onumulheres.org.br/wp-content/uploads/2013/03/convencao_cedaw1.pdf > Acesso em: 2 jul. 2018

ONU.ORGANIZAÇÃO DAS NAÇÕES UNIDAS. Assembleia Geral. Declaração e Programa de Ação de Viena. 1993 Disponível em: < http://www.onumulheres.org.br/wp-content/ uploads/2013/03/declaracao_viena.pdf >. Acesso em: 2 out. 2018

ONU. ORGANIZAÇÃO DAS NAÇÕES UNIDAS. Assembleia geral. Declaração e Plataforma de Ação da IV Conferência Mundial Sobre a Mulher de Pequim. 1995. Disponível em: < http:// unfpa.org.br/Arquivos/declaracao_beijing.pdf >. Acesso em: 2 out. 2018

ONU MULHERES. Prevenir Los Conflictos Transformar La Justicia Garantizar La Paz: Estudio mundial sobre la aplicación de la resolución 1325 del Consejo de Seguridad de las Naciones Unidas. 2015 Disponível em: < http://colombia.unwomen.org/es/biblioteca/ publicaciones/2016/04/prevenir-conflictos-transformar-justicia>. Acesso em: 12 nov. 2018

PIOVESAN, Flávia. Direitos Humanos e o Direito Constitucional Internacional. São Paulo: Editora Saraiva. 2011. p.7-23 /147-215

PNUD PROGRAMA DAS NAÇÕES UNIDAS PARA O DESENVOLVIMENTO.. Arab Human Development Report 2016: Youth and the Prospects for Human Development in a Changing Reality. Nova York, 2016 Disponível em: < http://www.arabstates.undp.org/content/dam/ rbas/report/AHDR\%20Reports/AHDR\%202016/AHDR\%20Final\%202016/AHDR2016En. pdf >. Acesso em: 1 nov. 2018

RAO, Arati. The politics of Gender and Culture in International Human Rights Discourse. in PETERS, Julie; Wolper, Andrea (Org.). Women`s Rights. Human Rigths: International Feminist Perspectives. Londres: Routledge,1995. p.103-114

SAID, Edward. Orientalismo: O Oriente como Invenção do Ocidente. São Paulo: Companhia das Letras, 2007. p.111-401

SHAHEED, Farida. Controlled or autonomous: identity and the experience of the network, women living under muslim laws. Signs, Chicago, v. 19, n. 4: p.997-1019,. jul./set. 1994. 


\section{artigo}

Disponível em:< https://www.jstor.org/stable/3175010?seq=1\#metadata_info_tab_contents $>$. Acesso em: 12 out. 2018

SIDANI, Yusuf. Women, work, and Islam in Arab societies. Women in Management Review, Beirut, v.20, n.7, p. 498-511, out/dez. 2005.Disponível em: <https://www.researchgate. net/publication/235273264_Women_work_and_Islam_in_Arab_societies?enrichId=rgreq-23c831e1ccac79041dd8d09d4e314b3c-XXX\&enrichSource=Y292ZXJQYWdlOzIzNTI3MzI2NDtBUzoyMzI2NjM0NTc50Dg2MDlAMTQzMjQ4MjY50TcxMQ\%3D\%3D\&el=1_x_2\&_ esc=publicationCoverPdf>. Acesso em: 1 nov. 2018

TICKNER, J. Ann. Gendering World Politics: Issues and approaches in the post Cold War era. Nova York: Columbia University Press. 2001. p.9-36

UNFPA. UNITED NATIONS FUND FOR POPULATION..Female Genital Mutilation Dashboard (FGM) - Mali. 2012. Disponível em <https://www.unfpa.org/data/fgm/ML\# > Acesso em 14 Out. 2018

WLUML. Women living Under Muslim Laws. About WLUML Disponível em: <http://www. wluml.org>. Acesso em: 19 mar. 2020 